\title{
STATISTICKÉ ZHODNOCENÍ SEISMICKÉ AKTIVITY ZÓNY MUR-MÜRZ-LEITHA
}

\author{
Statistical evaluation of the seismic activity of the Mur-Mürz-Leitha Zone
}

\section{Vít Rưžička}

Nové Syrovice 228, 67541 Nové Syrovice; e-mail: vitekruzicka@seznam.cz

Key words: Eastern Alps, Mur-Mürz-Leitha system, epicentral area Ebreichsdorf, recent tectonic activity, seismicity, earthquakes, earthquake distribution

\begin{abstract}
Mur-Mürz-Leitha fault system represents the most important seismically active zone in the Eastern Alps. Its part of the geological units of the Eastern Alps. Pushing the influence of alpine units to the north during the Cretaceous there was a lateral extrusion, resulting in the formation of shear fractures (eg.: system $M M L$ ). Based on data provided from the project ACORN, IPE and ZAMG. frequency-magnitude graph and temporal distribution chart since 1980 were compiled. Frequency-magnitude distribution show that borded of completeness of the data since 1980, have a value of magnitude 2 and higher. Therefore, the temporal distribution chart was created just since 1980, and magnitude of 2 and more. Above all the chart takes a set of occurrences of 2000, which number 37 events with a magnitude of 2 and 2 events with magnitude over 4 . These occurrences come under the area 4 . Then was made another temporal distribution chart since 1980, but this one is only for area 4. In area 4 Ebreichsdorf town is situated that is near the seismic swarm from the years of 2000 and 2013. The seismic swarm from 2013 is the similar like seismic swarm in 2000 just in a slightly smaller. These seismic occurrences of Ebreichsdorf are important, because they were macroseismic felt in the southern regions of the Czech Republic, including Brno.
\end{abstract}

\section{Úvod}

Studovaná oblast je součástí geologické jednotky Východních Alp, při kontaktu s jednotkou Českého masivu a Západních Karpat. Region byl konsolidován během alpinské orogeneze. Horotvorný proces byl zapříčiněn kolizí africké desky s deskou eurasijskou (Grad et al. 2009). Během období svrchní křídy dochází k posunu alpinských jednotek směrem k severu a následnému vyzdvihnutí celé oblasti (Ratschbacher et al. 1991). Pod vlivem tohoto sunutí docházelo k laterární extruzi, která měla za následek vznik střižných zlomů s orientací SV-JZ (Grad et al. 2009).

Tektonický systém Mur-Mürz-Leitha (dále MML) představuje horizontální posun s orientací SV-JZ (Reinecker - Lenhardt 1999). Systém je tvořen reaktivovanými strukturami miocenního stárí. Průměrná rychlost posunu zlomu je okolo $1-2 \mathrm{~mm}$ za rok a seismická aktivita je soustředěna do pruhu širokého $15-20 \mathrm{~km}$ podél zlomu (Reinecker - Lenhardt 1999). Systém je veden údolími řek Mur a Mürz. Na jihozápadě lze tuto zónu sledovat nejdále k ohybu řeky Mürz u Judenburgu. Na severovýchodním okraji je systém vymezován nejméně po oblast Malé Karpaty (Beidinger - Decker 2011; Linzer et al. 2002). Významná seismická aktivita je s tímto systémem spojena až od oblasti Semmeringu (Reinecker - Lenhardt 1999).

\section{Použitá zdrojová data}

Pro následné statistické vyhodnocení byla použita data mezinárodního projektu ACORN a bulletiny seismických jevů z ÚFZ (Ústav fyziky Země v Brně) a ZAMG (Ústřední ústav pro meteorologii a geodynamiku). Z výše zmíněných tří zdrojů byla sestavena databáze seismických jevů, která obsahuje data o jevech od roku 1267 do roku
2015 s prostorovou vazbou na systém MML (prostor vymezený červenými liniemi v obrázku 1). Takto sestavená databáze zahrnuje 808 seismických jevů, přičemž pouhých 24 jevů bylo zaznamenáno do roku 1900. Data $\mathrm{z}$ této databáze byla vynesena do mapy $\mathrm{v}$ podobě epicenter seismických jevů.

\section{Analýza seismických jevů}

Na základě hustoty epicenter bylo vymezeno území seismické aktivity zóny MML a toto území bylo následně rozděleno do 5 epicentrálních oblastí (obr. 1).Z grafu magnitudo-četnostní distribuce pro celý soubor dat (obr. 2) je zřejmé, že maximální naměřená hodnota magnituda v zóně MML je 5. Konkrétně se jedná o dva jevy, oba se shodnou hodnotou magnituda, které se uskutečnily 8. 5 . 1267 a 30. 4. 1885 u Kindbergu. Největší množství jevů má hodnotu magnituda v rozmezí 0,7-2,7 (obr. 2). Dále je zde patrný jev porušení lineárního trendu magnitudo-četnostní distribuce (dále ML) u hodnot magnituda nižších než 2,7-2,8 (Gutenberg - Richter 1944, 1945), z čehož vyplývá, že data pro ML menší než 2,7-2,8 nejsou kompletní. Pro starší jevy (např. středověké) platí, že práh ML, od kterého jsou data kompletní, bude ještě mnohem výše. Pro další statistiku bylo tedy nezbytné data časově omezit tak, aby se práh ML, od kterého budou data kompletní, snížil. Magnitudo-četnostní křivka např. od roku 1980 již vykazuje ztrátu lineárního trendu u $\mathrm{ML}=2$, což značí úplnost dat nad touto hodnotou pro časové období 1980-2015. Hodnota magnituda 2 spolu s časovým úsekem 35 let (1980-2015) poskytují dostatečný počet seismických jevů pro statistické vyhodnocení. Takto vzniklá databáze zahrnuje 537 seismických jevů. 


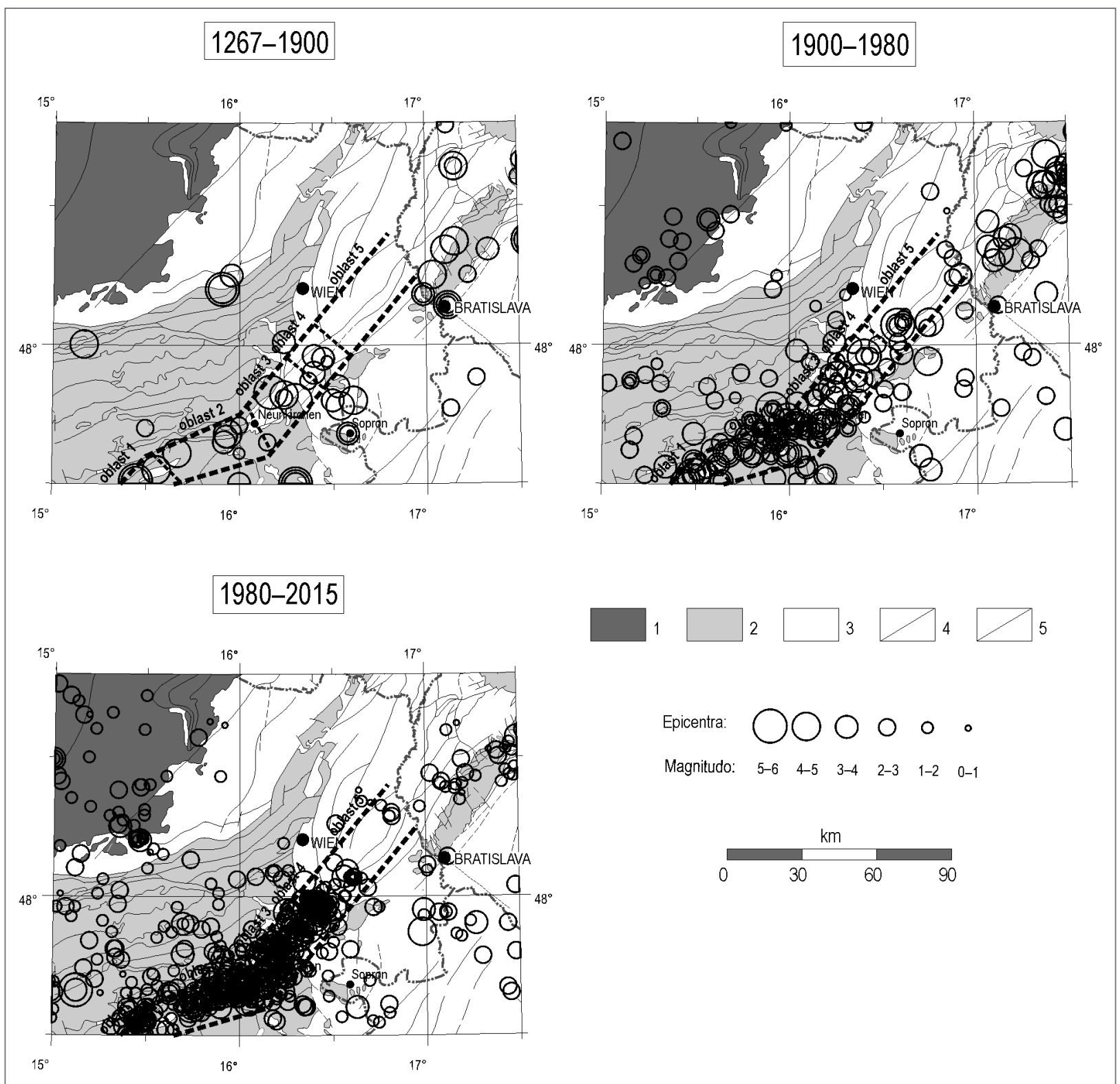

Obr. 1: Mapa epicenter zemětřesení (od roku 1267 do roku 2015) na podkladu schématické geologické mapy převzaté z práce Lenhardt et al. (2007), s vymezením zóny Mur-Mürz-Leitha a s rozdělením na jednotlivé oblasti (blíže viz text). Vysvětlivky: 1 - basement Českého masivu včetně paleozoického pokryvu; 2 - východní Alpy a Západní Karpaty; 3 - mesozoický pokryv Českého masivu; 4 - terciérní sedimentární pokryv Českého masivu a terciérní pokryv alpinské předhlubně a vídeňské pánve; 5 - kenozoické vulkanity; 6 - hlavní zlomy; 7 - předpolí př́krovů.

Fig. 1: Map of earthquake epicenters (from 1267 to 2015) on the base of schematic geological map taken from the work Lenhardt et al. (2007), defining zones Mur-Mürz-Leitha and the distribution of individual areas (see text). Explanations: 1 - Bohemian Massif including Paleozoic sedimentary cover; 2 - Eastern Alps and Western Carpathians; 3 - Mesozoic cover of the Bohemian Massif; 4 - Tertiary sedimentary cover of the Bohemian Massif and Tertiary sediments of the Alpine Foredeep and Vienna Basin; 5 - Cenozoic volcanic rocks; 6 - Major faults; 7 - Front of nappes.

V obrázku 3 zobrazujícím časovou distribuci zemětřesení v zóně MML od roku 1980 je patrný nárůst seismické aktivity (obr. 3 - písmeno „a“) v roce 2000, který číá 37 jevi̊ s hodnotou magnituda nad 2 a 2 jevy s hodnotou magnituda nad 4. Nadpoloviční většina těchto jevů byla zaznamenána v roce 2000 u Ebreischdorfu (obr. 4). Město Ebreichsdorf se nachází v epicentrální oblasti $430 \mathrm{~km}$ j. od Vídně. Z obrázku 4 je zřejmé, že k podobnému seismickému roji došlo v epicentrální oblasti u Ebreichsdorfu také $\mathrm{v}$ roce 2013. Na rozdíl od seismického roje v roce 2000 bylo v roce 2013 zaznamenáno 6 jevů s magnitudem nad 2 , ale 2 jevy s hodnotou magnituda nad 4 . V seismickém roji z roku 2000 byl nejsilnější jev zaznamenán 11.7.2000 s ML $=4,8$. V roji z roku 2013 to jsou jevy z 20. 9. a 2. 10., oba se shodnou hodnotou magnituda 4,2. Právě tyto 3 jevy byly makroseismicky pocítěny v jižních částech České republiky. Z této skutečnosti vyplývá, že epicentrální oblast u Ebreichsdorfu se seismicky projevovala v rámci MML v posledních desetiletích velmi výrazně. 


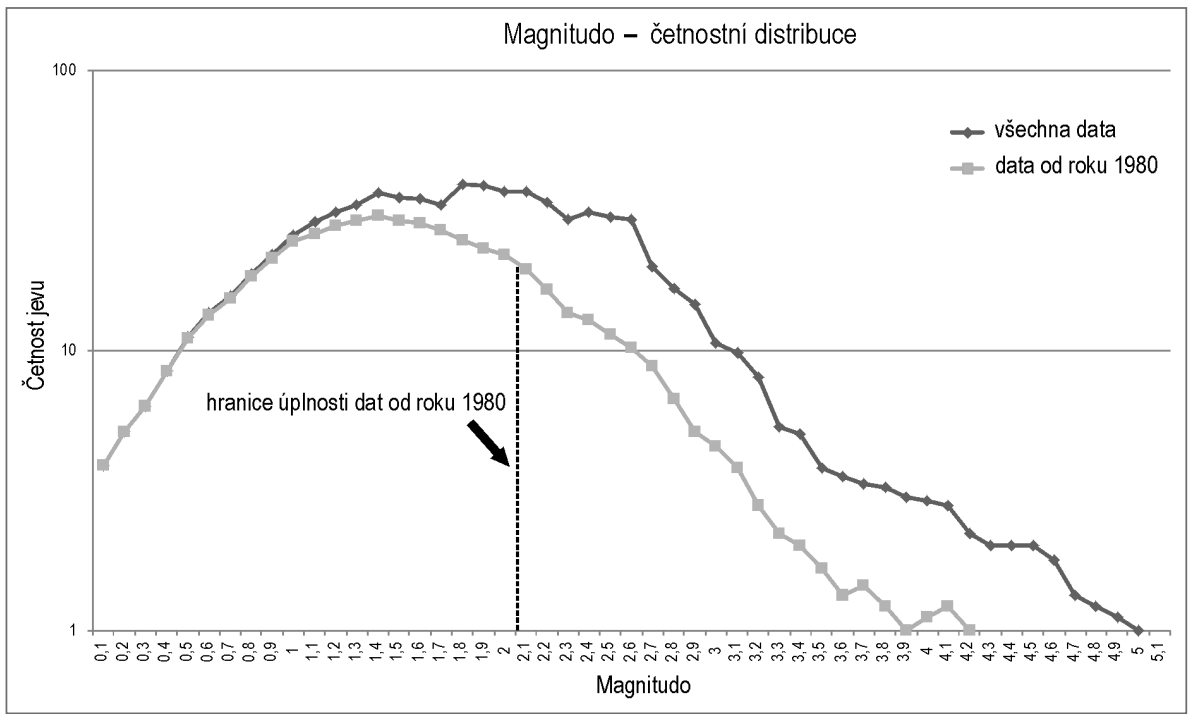

Obr. 2: Magnitudo-četnostní distribuce zemětřesení s epicentry prostorově vázanými $\mathrm{k}$ zóně MML; červená linie určuje hranici úplnosti dat od roku 1980.

Fig. 2: Frequency-magnitude graph of earthquakes with epicentres connected to MML system; red line determines border of completeness of the data since 1980.

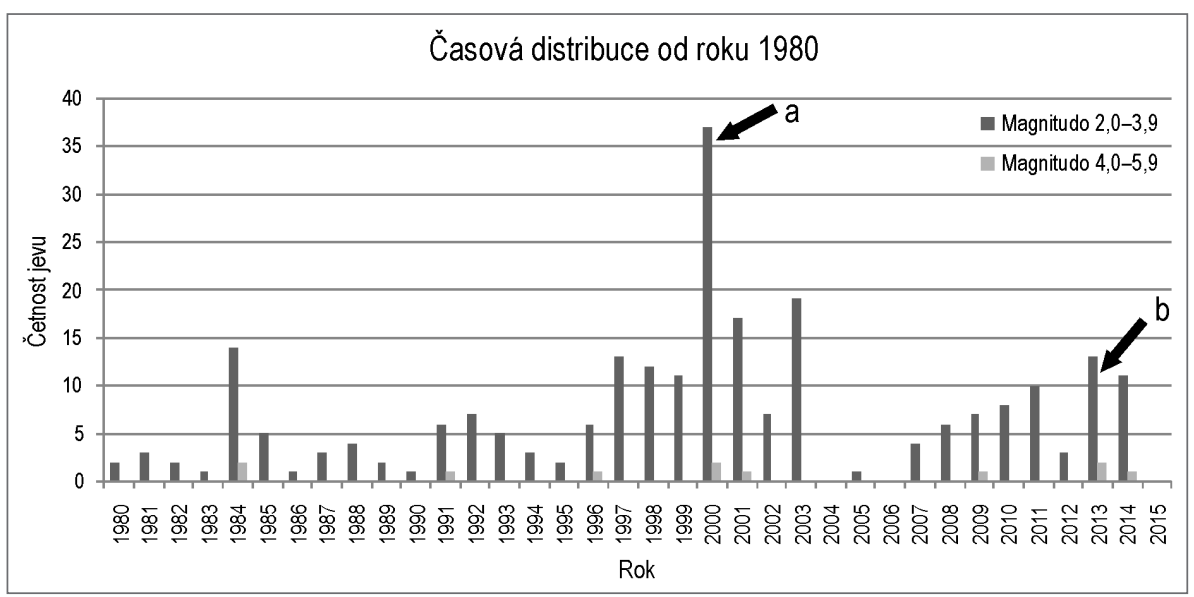

Obr. 3: Časová distribuce od roku 1980, zemětřesení s epicentry prostorově vázanými k zóně MML: a - soubor seismických jevů zahrnující jevy ze seismického roje u Ebreichsdorfu z roku 2000; b - soubor seismických jevů zahrnující jevy ze seismického roje u Ebreichsdorfu z roku 2013. Fig. 3: Temporal distribution of earthquakes with epicentres connected to MML system: a - set of seismic events involving occurrences of seismic swarm at Ebreichsdorf in 2000; b - set of seismic events involving occurrences of seismic swarm at Ebreichsdorf in 2013.

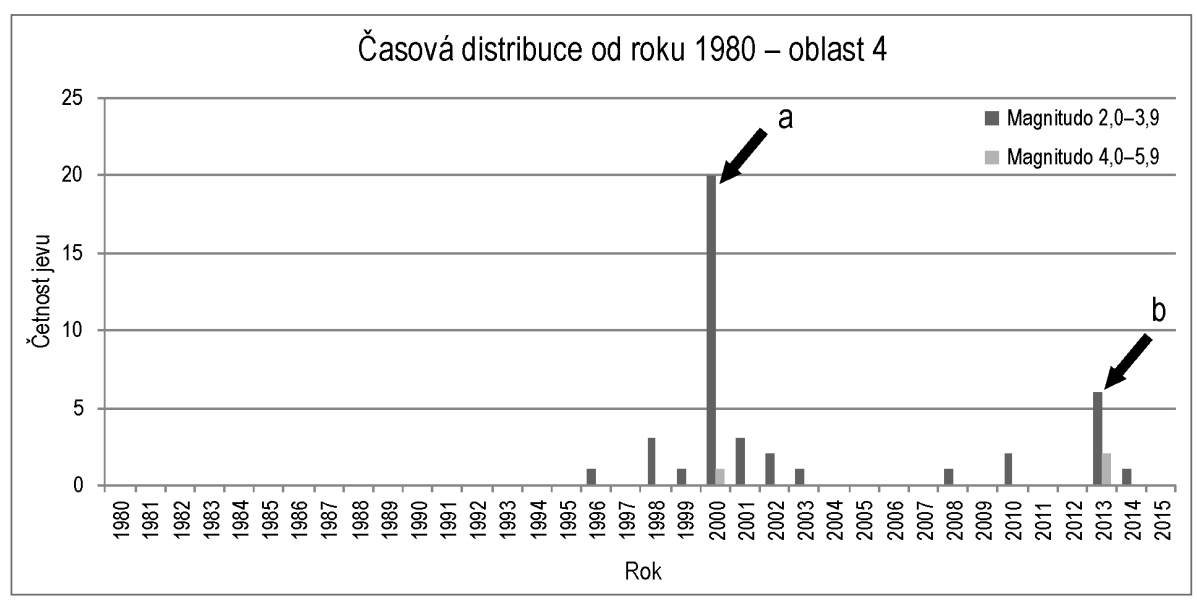

\section{Závěr}

Epicentrální oblast u Ebreichsdrofu se jeví jako velmi důležitá pro monitorování seismické aktivity v ČR právě proto, že v posledních desetiletích vykazuje zvýšenou seismickou aktivitu, která se makroseismicky projevila i na našem území. Zemětřesení z roku 2000 a 2013 byly pocítěny i v jižních částech České republiky, včetně Brna.

\section{Poděkování}

Rád bych poděkoval Mgr. Josefu Havírovi, Dr. za pomoc při tvorbě tohoto príspěvku a dále ÚFZ Brno za poskytnutá data.
Obr. 4: Časová distribuce zemětřesení s epicentry prostorově vázanými $k$ oblasti 4 : a - seismický roj u Ebreichsdorfu v roce 2000; b - seismický roj u Ebreichsdorfu v roce 2013.

Fig. 4: Temporal distribution of earthquakes with epicentres connected to area 4 : a - seismic swarm at Ebreichsdrof in 2000; b - seismic swarm at Ebreichsdrof in 2013. 


\section{Literatura}

Beidinger, A. - Decker, K. (2011): 3D geometry and kinematics of the Lassee flower structure: Implications for segmentation and seismotectonics of the Vienna Basin strike-slip fault, Austria. - Tectonophysics, 499, 1-4, 22-40.

Grad, M. - Brückl, E. - Majdański, M. et al. (2009): Crustal structure of the Eastern Alps and their foreland: seismic model beneath the CEL10/Alp04 profile and tectonic implications. - Geophysical Journal International, 177, 1, 279-295.

Gutenberg, B. - Richter, C. F. (1944): Frequency of earthquakes in California. - Bulletin of the Seismological Society of America, $34,4,185-188$.

Gutenberg, B. - Richter, C. F. (1945): Seismicity of the Earth: (Supplementary paper). - Geological Society of America Bulletin, $56,603-667$.

Lenhardt, W. - Švancara, J. - Melichar, P. et al. (2007): Seismic activity of the Alpine-Carpathian-Bohemian Massif region with regard to geological and potential field data. - Geologia Carphatica, 58, 397-412.

Linzer, H. - Decker, K. - Peresson, H. et al. (2002): Balancing lateral orogenic float of the Eastern Alps. - Tectonophysics, 354, 211-237.

Ratschbacher, L. - Merle, O. - Davy, P. et al. (1991): Lateral extrusion in the eastern Alps, Part 1: Boundary conditions and experiments scaled for gravity. - Tectonics, 10, 245-256. 